$\mathbb{T}$ periodica polytechnica

\author{
Transportation Engineering \\ $39 / 1(2011) 43,47$ \\ doi: 10.3311/pp.tr.2011-1.08 \\ web: http://www.pp.bme.hu/tr \\ (c) Periodica Polytechnica 2011
}

RESEARCH ARTICLE

\section{Calculation model for transport costing}

\author{
Zoltán Bokor
}

Received 2010-09-06

\begin{abstract}
Transport costing is a widely used information source for decision making processes in companies operating in the transport or logistics sector. The traditional costing methods, however, often neglect the proper allocation of indirect transport costs, which may lead to considerable distortions in costing information. Former researches have already elaborated the principles of improved transport cost calculation eliminating these methodological shortcomings and implemented the theory in pilot applications. This paper aims to build a generalised transport costing model on the basis of these principles and determine its mathematical formulas. The conditions of the practical implementation are also analysed. The main methodological contribution of the generalised transport costing model is the formalised inclusion of technology performance relations into the accounting based approach.
\end{abstract}

\section{Keywords \\ transport costs $\cdot$ transport performances $\cdot$ calculation}

\section{Acknowledgement}

This work is connected to the scientific program of the "Development of quality-oriented and harmonized $R+D+I$ strategy and functional model at BME" project. This project is supported by the New Hungary Development Plan (Project ID: TÁMOP4.2.1/B-09/1/KMR-2010-0002).

Zoltán Bokor

Department of Transport Economics, BME, Bertalan L. u. 2. H-1111 Budapest, Hungary

e-mail: zbokor@kgazd.bme.hu

\section{Introduction}

Cost calculation plays an important role in the management of transport companies. It delivers information for the decision making about the resource consumption and the performances delivered by the use of the resources. Reliable transport costing information is needed as it has a major impact on resource allocations.

Transport companies operate with a relatively high share of indirect costs. It can be explained by the common use of certain resources, which means that a considerable part of operation costs shall be allocated to the selected costing objects during the calculation. Traditional transport costing methods apply, however, very simplified allocation mechanisms, like direct cost based indirect cost assignment. It may distort cost information when evaluating transport services or organisational units. Moreover, the costing plans (budgets) rely on ad-hoc considerations rather than on exact effectiveness or efficiency indices [5].

The restructuring of traditional transport costing methods in practice is not an intensively researched topic. There are only few attempts published in the literature which aim at coping with the problem of arbitrary transport or logistics cost allocations [1,2] or deal with logistics performance management and measurement [6.7]. Nevertheless, the principles of a new transport cost calculation system have already been elaborated and applied in various pilot projects [3-5]. In the following these principles are generalised as a model and even transformed into mathematical formulas.

\section{The operation model}

Fig. 1 illustrates the operation model proposed for transport cost calculations based on cause-effect relations (represented by performances). It consists of the following elements:

- cost objects:

- central service cost objects $(i=1 \ldots \mathrm{n})$;

- productive cost objects $(j=1 \ldots \mathrm{m})$;

- transport tasks as profit objects $(k=1 \ldots 1)$;

- performance flows: 


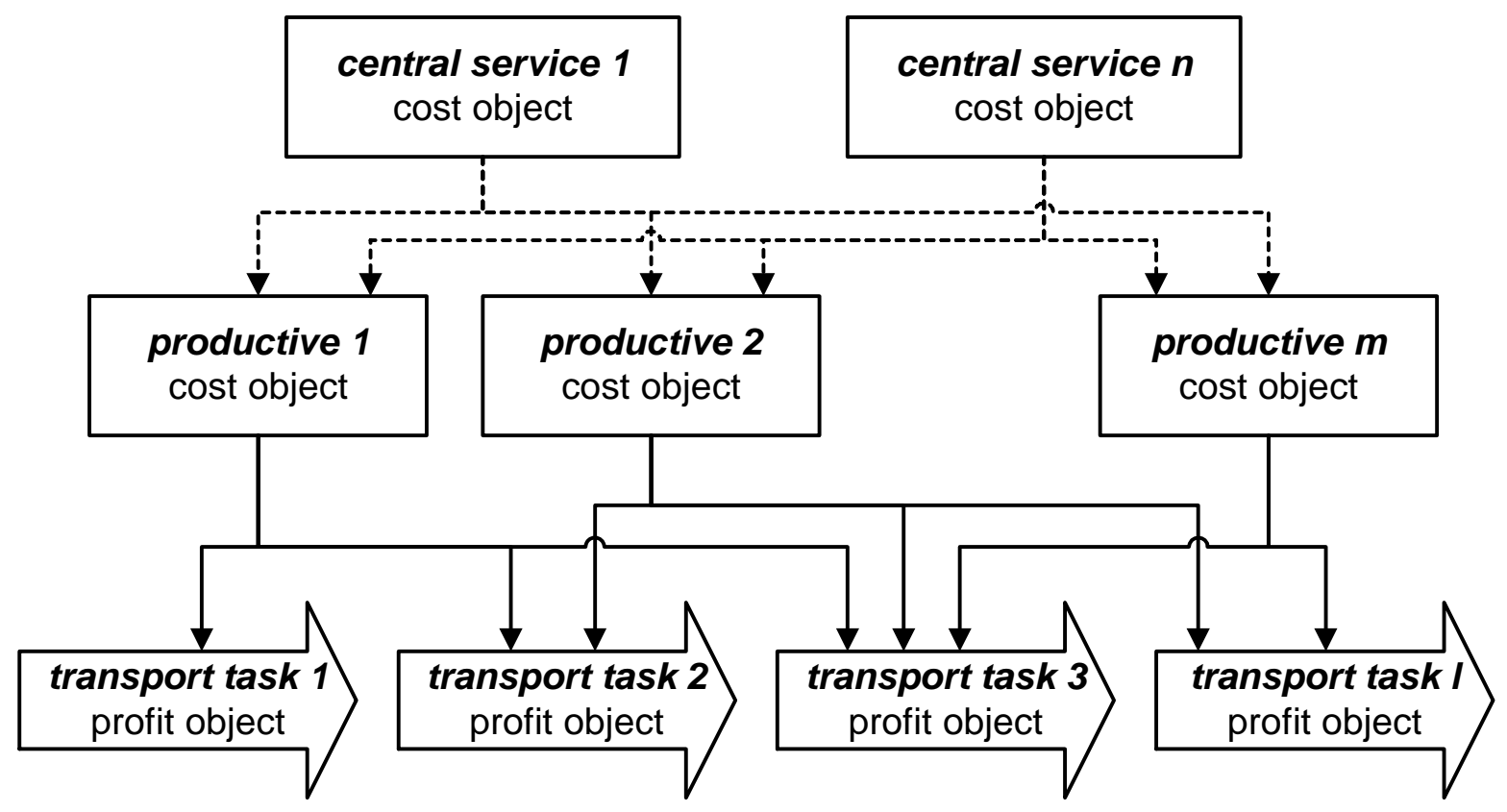

Fig. 1. The proposed operation model of transport costing

- between the central service and the productive profit objects;

- between the productive cost objects and the profit objects.

Cost objects are various organisation units or pieces of equipment in the transport company. The central service units are responsible for providing the productive units with background services (performances) like information technology, general management and accounting, marketing, human resource management, maintenance or accommodation. The productive cost objects are involved in the production of the transport tasks. Such cost objects can be for example: traffic planning, traffic management, disposition of various resources, vehicle operation, tracking and tracing, etc. [4 5]. The human and the material resources which can not be allocated to the transport tasks directly are assigned to the cost objects. So the operation costs of consuming these resources represent the indirect costs of the transport company. Thus indirect costs are collected in the cost objects.

Profit objects are the transport tasks produced by the company. So these are the "products" of the transport company. Profit objects create revenues while consume resources and performances. Profit object is for instance: a journey, a shipment, a service, a line, a service network, etc. [4,5]. Resources which can be allocated to the transport tasks directly (e.g. infrastructure user charges, fuel consumption, etc.) cause the direct transport costs. The indirect transport costs are allocated to the profit objects by monetising the performance flow coming from the productive cost objects. So the costs of the transport profit objects can be determined in an exact way. If revenues can also be allocated margins of profit objects become visible as well (this paper does not cover margin calculations).
Performance flows - often called as cost drivers - are used to model the cause-effect relationships as company-intern services. The performances can mainly be identified through investigating the technology processes. To measure the performance flow suitable performance indicators - depending on the technology shall also be selected. Such indicators can be for instance: area used, working hours, service hours, journey time, number of operations or transactions, vehicle kilometre, occupation time, distance, etc [3],4].

The data structure of the operation model has to be determined before setting up the calculation scheme - see Table 1 . Additional remarks to Table 1:

- fix and variable costs (at central service and productive cost objects):

- fix costs are independent from performance changes (e.g. linear depreciation, fixed salaries);

- variable costs depend on performance intensity (e.g. wages, materials used and extern services);

- primary and secondary costs (at productive cost objects):

- primary costs are the costs of resources assigned to the cost object;

- secondary costs are the costs of background services used (coming from the central service units);

- secondary fix costs are generally not relevant (fix costs are not allocated by using performance flows as they are independent from them).

\section{The cost calculation scheme}

In the following the basic mathematical formulas are developed for the transport cost calculation model. The first task is to create the costing formulas for the central service cost objects. 
Tab. 1. The data structure of the operation model

\begin{tabular}{lll}
\hline $\begin{array}{l}\text { Central service } \\
\text { cost object }\end{array}$ & Productive cost object & Profit object \\
\hline - fix costs & - primary fix costs & • direct costs \\
- variable costs & $\bullet$ (soutsecondary fix costs) & $\bullet$ indirect \\
- performance & • primary variable costs & costs \\
& $\bullet$ secondary variable costs & $\bullet$ (revenues) \\
& $\bullet$ performance &
\end{tabular}

The total cost of a certain central service unit consists of the fix and the variable cost items (1).

$$
C_{\operatorname{cocs}_{i}}=C_{\operatorname{cocs}_{f_{i}}}+C_{\operatorname{cocs}_{v_{i}}}
$$

where:

$C_{\text {cocs }_{i}}$ - total cost of central service cost object $i$;

$C_{\operatorname{cocs}_{f_{i}}}-$ fix cost of central service cost object $i$;

$C_{\operatorname{cocs}_{v_{i}}}$ - variable cost of central service cost object $i$.

If the relevant performance indicator is available the average (or specific) cost of the cost object can also be calculated (2). This is one of the most important efficiency measures as the ratio of costs and performances can be evaluated exactly for every central service unit. Outsourcing decisions may be supported by this information too. The specific cost can also be differentiated into fix and variable parts. The latter is necessary for cost allocations as it is used as the accounting price of the corresponding performance. It has to be noted that fix costs are not allocated as they are independent from performances so no cause-effect relationship exists between them.

$$
c_{\operatorname{cocs}_{i}}=\frac{C_{\operatorname{cocs}_{i}}}{P_{i}}=\frac{C_{\operatorname{cocs}_{f_{i}}}}{P_{i}}+\frac{C_{\operatorname{cocs}_{v_{i}}}}{P_{i}}=c_{\operatorname{cocs}_{f_{i}}}+c_{\operatorname{cocs}_{v_{i}}}
$$

where:

$c_{\text {cocs }_{i}}$ - average cost of central service cost object $i$;

$P_{i} \quad$ - performance of central service cost object $i$;

$c_{\operatorname{cocs}_{f_{i}}}$ - average fix cost of central service cost object $i$;

$c_{\operatorname{cocs}_{v_{i}}}$ - average variable cost of central service cost object $i$.

Moving to the calculation of the costs of the productive cost objects a more sophisticated approach is required: the cost items shall be further differentiated into primary and secondary parts (3). As mentioned before, secondary fix costs are not relevant for this model.

$$
C_{\operatorname{cop}_{j}}=C_{\operatorname{cop}_{f_{p_{j}}}}+C_{\operatorname{cop}_{v_{p_{j}}}}+C_{\operatorname{cop}_{v_{s_{j}}}}
$$

where:

$C_{\text {cop }_{j}}-$ - total cost of productive cost object $j$;

$C_{\text {cop }_{f_{p_{j}}}}$ - primary fix cost of productive cost object $j$;

$C_{\text {cop }_{v_{p_{j}}}}$ - primary variable cost of productive cost object $j$;

$C_{\text {cop }_{v_{s_{j}}}}$ - secondary variable cost of productive cost object $j$.
Here additional calculation is needed as the secondary costs of the productive cost objects are determined through the monetised performance consumption (4). It means that the performance consumption of the examined productive cost object has to be measured at every central service unit (it is 0 where no intern service connection exists).

$$
C_{\operatorname{cop}_{v_{s}}}=\sum_{i=1}^{n} P_{i j} c_{\operatorname{cocs}_{v_{i}}}=\sum_{i=1}^{n} C_{\operatorname{cocs}_{v_{i}}} \frac{P_{i j}}{P_{i}}
$$

where:

$P_{i j}$ - performance consumed by productive cost object $j$ at central service cost object $i$.

By inserting (4) into (3) the costing formula of productive cost objects becomes calculable 5 .

$$
C_{\operatorname{cop}_{j}}=C_{\operatorname{cop}_{f_{p_{j}}}}+C_{\operatorname{cop}_{v_{p_{j}}}}+\sum_{i=1}^{n} C_{\operatorname{cocs}_{v_{i}}} \frac{P_{i j}}{P_{i}}
$$

The average costs of productive cost objects can be determined similarly to Eq. (3), the resulting formula, however, is more complex due to the additional cost allocation. The average variable cost serves as accounting price (like before) when monetising the performance flows between productive cost objects and profit objects.

$$
\begin{aligned}
& c_{\text {cop }_{j}}= \frac{C_{\operatorname{cop}_{j}}}{P_{j}}=\frac{C_{\operatorname{cop}_{f_{p_{j}}}}}{P_{j}}+\left(\frac{C_{\operatorname{cop}_{v_{p}}}}{P_{j}}+\sum_{i=1}^{n} C_{\operatorname{cocs}_{v_{i}}} \frac{P_{i j}}{P_{i} P_{j}}\right)= \\
& c_{\operatorname{cop}_{f_{j}}}+c_{\operatorname{cop}_{v_{j}}}
\end{aligned}
$$

where:

$c_{c p_{j}}$ - average cost of productive cost object $j$;

$P_{j} \quad$ - performance of productive cost object $j$;

$c_{\text {cop }_{f_{j}}}$ - average fix cost of productive cost object $j$;

$c_{c p_{v_{j}}}$ - average variable cost of productive cost object $j$.

The costs of profit objects (transport tasks) are the sum of direct and indirect cost items (7).

$$
C_{p o_{k}}=C_{p o_{d_{k}}}+C_{p o_{i d_{k}}}
$$

where:

$C_{p o_{k}}-$ total cost of profit object $k$;

$C_{p o_{d_{k}}}$ - direct cost of profit object $k$;

$C_{p o_{i d_{k}}}$ - indirect cost of profit object $k$.

The indirect costs of profit objects can be calculated similarly to formula (4). Nevertheless, based on the corresponding performance ratios, a doubled cost allocation is needed here 8 .

$$
\begin{aligned}
& C_{p o_{i d_{k}}}=\sum_{j=1}^{m} P_{j k} c_{\operatorname{cop}_{v_{j}}}=\sum_{j=1}^{m} C_{\operatorname{cop}_{v_{p_{j}}}} \frac{P_{j k}}{P_{j}} \\
& +\sum_{j=1}^{m} \sum_{i=1}^{n} C_{\operatorname{cocs}_{v_{i}}} \frac{P_{i j} P_{j k}}{P_{i} P_{j}}
\end{aligned}
$$

where: 
Tab. 2. The characteristics of the traditional and the improved transport costing methods

\begin{tabular}{|c|c|}
\hline Traditional costing method & Improved costing method \\
\hline $\begin{array}{l}\text { Advantages: } \\
\text { - simple method } \\
\text { - less input data necessary } \\
\text { - the total prime costs are calculated }\end{array}$ & $\begin{array}{l}\text { Advantages: } \\
\text { - indirect cost allocations are supported through a clear and trans- } \\
\text { parent methodology } \\
\text { - more reliable and correct cost information in the elementary levels } \\
\text { of object hierarchy } \\
\text { - additional information is available on the cost efficiency of perfor- } \\
\text { - } \text { mances }\end{array}$ \\
\hline $\begin{array}{l}\text { Disadvantages: } \\
\text { - indirect costs are allocated on arbitrary bases } \\
\text { - cause-effect relations are ignored } \\
\text { - fix and variable cost items are not differentiated } \\
\text { - yields distorted cost information in the lower levels of object hier- } \\
\text { archy }\end{array}$ & $\begin{array}{l}\text { Disadvantages: } \\
\text { - complicated method } \\
\text { - needs an extensive and duly structured input cost database } \\
\text { - additional data collection is needed (at least: performance intensi- } \\
\text { ties) } \\
\text { - fix costs are not considered in the lower levels of object hierarchy }\end{array}$ \\
\hline
\end{tabular}

$P_{j k}-$ performance consumed by profit object $k$ at productive cost object $j$.

By inserting (8) into (7) the cost calculation formula - of a certain transport task -based on the modelling of exact causeeffect relations (represented by the performance indicators - or their ratios - as cost drivers) can be set up as follows (9):

$$
C_{p o_{k}}=C_{\text {po }_{d_{k}}}+\sum_{j=1}^{m} C_{\operatorname{cop}_{v_{p}}} \frac{P_{j k}}{P_{j}}+\sum_{j=1}^{m} \sum_{i=1}^{n} C_{\operatorname{cocs}_{v_{i}}} \frac{P_{i j} P_{j k}}{P_{i} P_{j}}
$$

It is worth comparing Eq. (9) with the simple calculation formula of direct cost based indirect cost allocation (10). It is obvious that the use of the simple model may lead to distorted transport costing information as it ignores detailed cost differentiations and applies an arbitrary allocation procedure: a fixed $\%$ of direct costs is added as indirect cost.

$$
C_{p o_{k}}=C_{p o_{d_{k}}}+C_{i d} \frac{C_{p o_{d_{k}}}}{\sum_{k=1}^{l} C_{p o_{d_{k}}}}=C_{p o_{d_{k}}}\left(1+\frac{C_{i d}}{\sum_{k=1}^{l} C_{p o_{d_{k}}}}\right)
$$

where:

$C_{i d}-$ total indirect cost of the transport company.

Coming back to Eq. (9), it is to be noted that the equation contains no fix cost elements. This is the consequence of the methodological principle applied: no cause-effect based driver (performance indicator) is available for fix cost allocations in the level of elementary cost and profit objects. That is why it is essential to define fix and variable cost items carefully.

Thus fix costs are taken into account in higher aggregation levels: when calculating the "tightened" total cost - here the fix costs of central units are excluded - (11) or the total cost (12) of the transport company. The ratio of fix and variable costs becomes transparent by these cost aggregations while cost coverage ratios can also be evaluated. The latter analysis needs the inclusion of revenue data too.

$$
C_{1}=\sum_{k=1}^{l} C_{p o_{k}}+\sum_{j=1}^{m} C_{\operatorname{cop}_{f_{p_{j}}}}
$$

where:

$C_{1} \quad$ - "tightened" total cost of the transport company.

$C_{2}=C_{1}+\sum_{i=1}^{n} C_{\operatorname{coss}_{f_{i}}}=\sum_{k=1}^{l} C_{\text {po }_{k}}+\sum_{j=1}^{m} C_{\operatorname{cop}_{f_{p_{j}}}}+\sum_{i=1}^{n} C_{\operatorname{cocs}_{f_{i}}}$

where:

$C_{2}-$ total cost of the transport company.

\section{Implementation issues}

The implementation of the proposed transport cost calculation model requires a sound database where the input data are available in the requested format. The following cost data shall be collected:

- the costs of central service cost objects differentiated into fix and variable parts;

- the primary costs of productive cost objects differentiated into fix and variable parts;

- the direct costs assigned to profit objects;

- (the revenues assigned to profit objects - when margin calculations are performed).

It is often not possible to exploit these data from the general ledger directly as the data structure of the accounting system 
differs from the one of the cost calculation. In this case additional data pre-processing may be needed before starting the calculation procedure.

Another problem in the field of cost data may arise when the differentiation of fix and variable cost items can not be managed. It is usual as accounting systems apply generally no such differentiations. This problem can be overcome by using simple integrated cost data which make the calculation formulas less difficult. Of course this simplification may lead to information losses but the cost allocations remain still on a cause-effect basis.

The collection of the detailed technology performance input data is a new task as the traditional accounting systems do not use such information (or they use them in aggregated forms only). The following performance data shall be made available:

- performances of central service cost objects;

- performances of productive service cost objects;

- performance flows between central service and productive cost objects;

- performance flows between productive cost objects and profit objects.

These data can be extracted from the technology information systems supporting the operative planning and controlling of transport processes. If the performance data are to be used for cost allocations exclusively (so no average costs are analysed) it is sufficient to assess the performance flows. Moreover, the cost calculation formulas (Eqs. (5) and (97) require the availability of performance intensities only (Eqs. (13) and (14)).

$$
p_{i j}=\frac{P_{i j}}{P_{i}}
$$

where:

$p_{i j} \quad$ - performance intensity between central service cost object $i$ and productive cost object $j$.

$$
p_{j k}=\frac{P_{j k}}{P_{j}}
$$

where:

$p_{j k}-$ performance intensity between productive cost object $j$ and profit object $k$.

The performance intensity data can be summarised in matrices (see Fig. 2). These matrices are the core elements of the developed cost calculation scheme as they represent the cost drivers - corresponding to the transport technology operations - which make the allocation procedure more exact. Thus, if these matrices can be made available and accessible the analysts might obtain an up-to-date and transparent transport costing mechanism.

The complexity (i.e. the amount of details in the data structure) of the costing model depends on several factors like:

- the size and the range of activities in the transport company;

$$
\left[\begin{array}{llll}
p_{11} & p_{12} & \ldots & p_{1 m} \\
p_{21} & p_{22} & \ldots & p_{2 m} \\
\ldots & \ldots & p_{i j} & \ldots \\
p_{n 1} & \ldots & \ldots & p_{n m}
\end{array}\right]\left[\begin{array}{llll}
p_{11} & p_{12} & \ldots & p_{1 l} \\
p_{21} & p_{22} & \ldots & p_{2 l} \\
\ldots & \ldots & p_{j k} & \ldots \\
p_{m 1} & \ldots & \ldots & p_{m l}
\end{array}\right]
$$

Fig. 2. The performance intensity matrices

- the information demand (which transport objects are to be examined);

- the quality of the input data;

- the information sources (manually managed or computerised inputs).

\section{Conclusions}

The proposed model makes transport costing more reliable but at the same time it requires more or additional resources. In any case, it delivers a significant methodological improvement in comparison to the traditional cost calculation methods. Table 2 gives a comparison of the two, basically different, approaches.

The following questions can be answered by using the modelled cause-effect costing relations:

- which transport activities yield profits or cause losses;

- what are the reasons behind profits or losses (e.g. the costs, the performances, their ratio or the price determined);

- what is the efficiency of various transport performance productions;

- where are the bottlenecks in the transport process structure;

- what happens if transport operation costs are reduced, etc. (effect analysis).

So the developed model is not only a cost calculation scheme but - after its implementation - it can be used as a decision support tool as well. Its main methodological contribution is the formalised integration of technology considerations into the accounting based costing procedures.

\section{References}

1 Askarany D, Yazdifar H, Askary S, Supply chain management, activitybased costing and organisational factors, International Journal of Production Economics 127 (2010), no. 2, 238-248, DOI 10.1016/j.ijpe.2009.08.004.

2 Baykasoglu A, Kaplanoglu V, Application of activity-based costing to a land transportation company: a case study, International Journal of Production Economics 116 (2008), no. 2, 308-324, DOI 10.1016/j.ijpe.2008.08.049.

3 Bokor Z, Cost Drivers in Transport and Logistics, Periodica Polytechnica ser. Transportation Engineering 38 (2010), no. 1, 13-17, DOI 10.3311/pp.tr.2010-1.03.

4 , Implementation of Activity-based Costing in Logistics, Acta Technica Jaurinensis ser. Logistica 2 (2009), no. 3, 337-343.

5 _ Elaborating Cost and Performance Management Methods in Transport, Promet - Traffic \& Transportation 21 (2009), no. 3, 217-224.

6 Cai J, Liu X, Xiao Z, Liu J, Improving supply chain performance management: A systematic approach to analyzing iterative KPI accomplishment, Decision Support Systems 46 (2009), no. 2, 512-521, DOI 10.1016/j.dss.2008.09.004.

7 Fawcett S E, Cooper M B, Logistics Performance Measurement and Customer Success, Industrial Marketing Management 27 (1998), no. 4, 341-357, DOI 10.1016/S0019-8501(97)00078-3. 